Rev. Bras. Saúde Prod. Anim., Salvador, v.15, n.1, p.237-247 jan./mar., 2014 http://www.rbspa.ufba.br ISSN 15199940

\title{
Desempenho de bezerros leiteiros em aleitamento artificial convencional ou fracionado
}

\author{
Performance of dairy calves in artificial fed milk conventional or fractionated
}

\author{
AZEVEDO, Rafael Alves de ${ }^{1 *}$; RUFINO, Sâmara Raiany de Almeida ${ }^{2}$; DUARTE, \\ Douglas Vinícius Lage ${ }^{2}$; SOARES, Ana Claudia Maia²; GERASEEV, Luciana Castro ${ }^{2}$
}

\footnotetext{
${ }^{1}$ Universidade Federal de Minas Gerais, Escola de Veterinária, Belo Horizonte, Minas Gerais, Brasil.

${ }^{2}$ Instituto de Ciências Agrárias da Universidade Federal de Minas Gerais, UFMG.

*Endereço para correspondência: rafaelzooufmg@gmail.com
}

\section{RESUMO}

Objetivou-se avaliar o consumo, o desempenho e a incidência de diarreia de bezerros da raça Holandesa, além de realizar análise técnica e econômica dos sistemas artificiais de aleitamento convencional e fracionado. Foram utilizados 22 animais, sendo 12 machos e 10 fêmeas, com peso corporal inicial médio de $37,26 \mathrm{~kg}( \pm 3,42)$, distribuídos em delineamento em blocos casualizados, de acordo com o sexo, alojados em baias individuais até os 59 dias de idade dos animais. $\mathrm{O}$ aleitamento convencional constituiu-se de quatro litros de leite diários durante 59 dias e o fracionado, de seis litros do $6^{\circ}$ ao $25^{\circ}$; quatro litros do $26^{\circ}$ ao $45^{\circ}$ e dois litros do $46^{\circ}$ ao $59^{\circ}$ dia de idade, além de concentrado, de feno de Cynodon sp., de água e de suplemento mineral fornecidos ad libitum. $\mathrm{O}$ consumo dos alimentos e incidência de diarreia foram monitorados diariamente e os animais, pesados e medidos, semanalmente. Os dados de consumo, de ganho de peso diário, medidas de crescimento, conversão alimentar e a incidência de diarreia foram analisados em parcelas subdivididas. $\mathrm{O}$ ganho total corporal e o peso corporal final foram analisados em delineamento em blocos casualizados. $\mathrm{O}$ peso corporal inicial foi utilizado como covariável. $\mathrm{O}$ sistema de aleitamento não interferiu $(\mathrm{p}>0,05)$ nos consumos de concentrado, feno, água e o desempenho dos animais. $\mathrm{O}$ aleitamento fracionado proporcionou maior $(\mathrm{p} \leq 0,05)$ consumo total de matéria seca no terceiro período de avaliação e menor custo por $\mathrm{kg}$ de ganho de peso total, indicando-o como melhor estratégia na bovinocultura leiteira.

Palavras-chave: análise econômica, bovino, diarreia, ganho de peso, leite

\section{SUMMARY}

This study aimed to evaluate the intake, performance and incidence of diarrhea in Holstein dairy calves, besides perform the technical and economic analysis of the artificial fed milk conventional and fractionated. Were used 22 animals, 12 males and 10 females, with an average initial of body weight of $37.26 \mathrm{~kg}$ $( \pm 3.42)$, allotted in a randomized block design housed in individual pens until 59 days old of animals. The feed milk conventional consisted of four liters of milk daily for 59 days and fractionated, six liters of $6^{\circ}$ to $25^{\circ}$, four liters of $26^{\circ}$ to $45^{\circ}$ and two liters of $46^{\circ}$ to $59^{\circ}$ days old, besides of starter, hay Cynodon sp., water and mineral supplement provided ad libitum. The food consumption and incidence of days with diarrhea were monitored daily and the animals were weighed and measured weekly. The consumption data, daily weight gain, measures of growth, feed conversion and the incidence of days with diarrhea were analyzed in split plot. The total gain and final body weight were analyzed in a randomized block design. The initial body weight was used as a covariate. The nursing system did not affect $(p>0.05)$ hay and water intakes, and animal performance. The fractionated breastfeeding provided greater $(\mathrm{p} \leq 0.05)$ dry matter total intake of in the third period of evaluation and lowest cost per kilogram of total weight gain, indicating it is a best strategy as in dairy cattle.

Keywords: cattle, diarrhea, economic analysis, milk, weight gain 


\section{INTRODUÇÃO}

Durante o aleitamento, a recomendação convencional adotada mundialmente, consiste no fornecimento da dieta líquida de modo restrito (HILL et al., 2006; UYS et al., 2011), em aproximadamente $10 \%$ do peso corporal do animal, de tal modo que um bezerro de $40 \mathrm{~kg}$ receberia quatro litros de leite ou de sucedâneo por dia, dividido em duas refeições (KMICIKEWYCZ et al., 2013). Entretanto, esse sistema vem sendo frequentemente associado a baixo desempenho e ineficiência alimentar (KHAN et al., 2007), além de comportamentos sugestivos de fome (JENSEN \& HOLM, 2003; VIEIRA et al., 2008) e maiores riscos de doenças (GODDEN et al., 2005; KHAN et al., 2007), demonstrando que esse método de alimentação pode reduzir o bem estar dos bezerros (Von KEYSERLINGK et al., 2009).

O sistema de aleitamento fracionado é uma alternativa ao aleitamento convencional (SWEENEY et al., 2010). Esse sistema consiste no fornecimento da dieta líquida acima de $10 \%$ do peso corporal por bezerro nas semanas inicias de vida, com posteriores reduções antes do desaleitamento, com o objetivo de estimular o consumo de matéria seca pelos animais.

A adoção de aleitamento fracionado pode permitir que os bezerros recebam quantidade de dieta líquida mais próxima ao que teriam em sistema com acesso ad libitum nas primeiras semanas de vida, entretanto, o maior fornecimento dessa dieta pode estar associada com menores consumos de concentrado (JASPER \& WEARY, 2002; PASSILLÉ et al., 2008) e aumento da frequência de diarreia (BROWN et al., 2005).
Análises dos efeitos dessa estratégia de aleitamento no desempenho dos animais são fundamentais para escolha da melhor opção a ser adotada nas propriedades, e há necessidade de estudos em face ao alto custo da dieta líquida e a dificuldade de escolher qual o melhor momento para aumentar a dieta sólida e diminuir a dieta líquida na criação de bezerros leiteiros.

Assim, objetivou-se avaliar o consumo, desenvolvimento e a frequência de diarreia de bezerros leiteiros Holandeses, bem como realizar análise econômica dos sistemas de aleitamento fracionado e convencional.

\section{MATERIAL E MÉTODOS}

O experimento foi conduzido no Setor de Bovinocultura Leiteira do Instituto de Ciências Agrárias da Universidade Federal de Minas Gerais (ICA/UFMG), Montes Claros, MG, Brasil, sendo os procedimentos avaliados e aprovados pelo Comitê de Ética em Experimentação Animal da UFMG, sob o protocolo 39/2009. Durante o período experimental a região apresentou médias de temperatura máxima e mínima de 33,3 e $13,6^{\circ} \mathrm{C}$, enquanto a umidade relativa do ar oscilou entre 80,6 e $54,5 \%$ (GEMISA, 2013).

Foram utilizados 22 bezerros da raça Holandesa, 12 machos e 10 fêmeas, na mesma idade, com peso corporal inicial médio de $37,26 \mathrm{~kg}( \pm 3,42)$, provenientes da Fazenda Experimental Professor Hamilton Navarro - FEHAM. Os animais foram distribuídos em delineamento em blocos casualizados, de acordo com o sexo, em dois tratamentos: aleitamento convencional, com quatro litros de leite diários, e aleitamento fracionado, com seis, quatro e dois litros de leite diários do $6^{\circ}$ ao $25^{\circ}$, do $26^{\circ}$ ao $45^{\circ}$ e do $46^{\circ}$ ao 
$59^{\circ}$ dias de idade, respectivamente, sendo alojadas em baias individuais com dimensionamento de $1,20 \mathrm{~m}$ de largura, $2 \mathrm{~m}$ de comprimento e $1,30 \mathrm{~m}$ de altura, contendo cama de areia.

A partir do sexto dia o leite foi ofertado em mamadeiras com capacidade de dois litros. Todos os grupos foram alimentados em duas refeições diárias de volumes equivalentes aos tratamentos, as oito e 16 horas, retirando-se a água 30 minutos antes e após o fornecimento.

Diariamente, pela manhã, foi trocada a água e à tarde foram renovados o concentrado peletizado e o feno inteiro de Cynodon sp., ofertados ad libitum, em comedouros de plástico, ajustando-se as sobras em $100 \mathrm{~g} \mathrm{~kg}^{-1}$. O suplemento mineral foi fornecido ad libitum. O leite utilizado foi obtido de vacas da raça Holandesa pertencentes à FEHAM em diferentes ordens e períodos de lactação. O leite foi fornecido imediatamente após a ordenha dos animais.

O leite utilizado foi analisado no Laboratório de Análise de Leite Escola de Veterinária da UFMG, Belo Horizonte, Minas Gerais, Brasil. A composição média foi de $3,0 \%$ de proteína bruta, $4,7 \%$ de gordura, $4,4 \%$ de lactose e $12,0 \%$ de sólidos totais. A matéria seca, proteína bruta, matéria mineral e extrato etéreo foram determinados de acordo com Silva \& Queiroz (2002), sendo as análises realizadas no Laboratório de Bromatologia (ICA/ UFMG) (Tabela 1).

Tabela 1. Composição bromatológica do concentrado e do feno de Cynodon sp.

\begin{tabular}{lcc}
\hline Variável & Concentrado & Feno $^{2}$ \\
\hline Matéria Seca (\% da Matéria Natural) & 87,00 & 93,00 \\
Matéria Mineral (\% da Matéria seca (MS)) & 6,95 & 5,35 \\
Proteína Bruta (\% da MS) & 19,00 & 12,10 \\
Extrato Etéreo (\% da MS) & 3,00 & 1,85 \\
\hline
\end{tabular}

${ }^{1}$ Concentrado comercial peletizado, Tecnutri Bezerro Elite (Níveis de garantia: mínimo de 0,60 e máximo de $1 \%$ de cálcio; $0,46 \%$ de fósforo e $8 \%$ de fibra bruta), empresa Tecnutri ${ }^{\circledR}$, Montes Claros, Minas Gerais, Brasil.

${ }^{2}$ Análises realizadas no Laboratório de Bromatologia do Instituto de Ciências Agrárias da Universidade Federal de Minas Gerais.

Avaliou-se o consumo de alimentos, o desenvolvimento corporal e a incidência de diarreia, do sexto ao $59^{\circ}$ dia de idade, totalizando 54 dias de avaliação. Os consumos de concentrado, feno e água foram obtidos por diferença entre a quantidade fornecida e as sobras do dia seguinte. Para os cálculos de consumo de água descontou-se a evaporação diária aferida em balde de referência por proveta com capacidade de $1000 \mathrm{~mL}$.

As variáveis de consumo foram mensuradas pela determinação do consumo diário de concentrado (CC), de feno $(\mathrm{CF})$ e do total de matéria seca
(CTMS), considerando-se a matéria seca do concentrado, do feno e da dieta líquida, e a conversão alimentar da matéria seca ingerida (CAMS), além do consumo de água (CA).

A partir dos seis dias de idade, antes do fornecimento das dietas, semanalmente, com intervalos fixos de sete dias, os animais foram pesados e a altura de cernelha e a circunferência torácica foram mensuradas com fita métrica, em duas repetições, sendo realizadas em local plano, permitindo que os animais permanecessem com os membros bem implantados ao solo. O desenvolvimento 
produtivo dos animais foi aferido por meio do ganho de peso diário (GPD), ganho de peso total (GT), altura de cernelha $(\mathrm{AC})$ e circunferência torácica (CT).

A avaliação diária da incidência de diarreia foi feita nos 54 dias experimentais, no período da manhã, e seguiu os parâmetros de consistência fecal segundo escores, de 1 a 4 , propostos por Lucci (1989), sendo consideradas fezes normais (1): firmes, mas não duras, com forma original levemente distorcida quando cai no chão e se assentam; fezes moles (2): sem forma, embora forme montes, se espalha levemente; fezes correntes (3): se esparrama rapidamente em lâmina de seis $\mathrm{mm}$ de profundidade e fezes aquosas (4): com consistência líquida. As incidências de escore 1, 2, 3 e 4 foram determinadas pelo número de dias com o respectivo escore em relação aos dias até a desmama, sendo o 1 e 2 considerados normais. A ocorrência de dias de diarreia foi reportada pelo somatório das observações do número de dias com os escores 3 e 4 .

Procedeu-se à análise estatística, em delineamento em blocos casualizados para o peso corporal final e ganho total no período total de avaliação (6 a 59 dias de idade), sendo aplicado o teste de Tukey a $5 \%$ de probabilidade, utilizandose o programa estatístico SAS versão 9.0 (STATISTICAL ANALYSIS SYSTEM, 2002). Os dados de consumo, de desempenho produtivo e de incidência de dias com diarreia foram analisados em parcelas subdivididas (dois sistemas nas parcelas e três períodos nas subparcelas), utilizando-se o teste de Tukey a 5\% de probabilidade, com o programa estatístico SAS (STATISTICAL ANALYSIS SYSTEM, 2002). O peso corporal inicial dos bezerros foi utilizado como covariável.
Para a análise econômica descritiva foram calculadas as variações nos custos com alimentação. Calculou-se o valor de cada componente da dieta e as variáveis de custo total com a alimentação e o custo por $\mathrm{kg}$ de ganho de peso. $\mathrm{O}$ valor individual dos insumos foi calculado multiplicando-se o consumo total de cada item pelos respectivos valores de mercado atual. $\mathrm{O}$ custo total de alimentação foi obtido com a soma dos custos individuais do concentrado, feno e leite (LIMA et al., 2012). O custo por $\mathrm{kg}$ de ganho de peso foi gerado com a divisão do custo total de alimentação pelo ganho de peso total. A porcentagem de custo de cada componente presente na dieta foi calculada em relação à participação percentual de cada um sobre o custo total da dieta.

As cotações do leite foram estimadas com as médias dos preços pagos aos produtores de Minas Gerais durante o período experimental, segundo o Centro de Estudos Avançados em Economia Aplicada (CEPEA, 2011). Os preços do concentrado e do feno foram obtidos nas empresas fornecedoras dos produtos.

\section{RESULTADOS E DISCUSSÃO}

Devido às estratégias de aleitamento pré-determinadas, o consumo médio de leite em cada período, em litros dia $^{-1}$, foi diferente entre os dois grupos avaliados de acordo com o período de avaliação. $\mathrm{O}$ consumo médio no primeiro período do tratamento fracionado foi superior $(p \leq 0,05)$ à quantidade oferecida ao tratamento convencional. No segundo período, ambos os sistemas ofertaram a mesma quantidade de leite aos animais, e, no terceiro período, os animais do grupo fracionado consumiram menores $(p \leq 0,05)$ quantidades de leite quando 
comparados aos animais alimentados convencionalmente. Em ambos os sistemas, independente do período de avaliação, todo o leite fornecido foi consumido pelos animais.

$\mathrm{O}$ fracionamento proposto considera o leite o alimento mais indicado para os bezerros (ORSKOV, 1972) durante o aleitamento, entretanto, a capacidade digestiva aumenta durante os primeiros meses de vida, de acordo com o perfil enzimático do trato digestório desses animais, e a digestão de proteínas e carboidratos mais complexos se torna mais eficiente, estimulada pela ingestão de alimentos sólidos (LE HUEROULURON et al., 1992).

Pode ser observado efeito $(\mathrm{p}>0,05)$ dos sistemas de aleitamento para o consumo de concentrado, sendo observada uma superioridade em $18,7 \%$ de consumo para os animais aleitados de forma fracionada (Tabela 2). $\mathrm{O}$ período influenciou esse parâmetro $(\mathrm{p} \leq 0,05)$, com valores crescentes durante $o$ período avaliado para ambos os sistemas de aleitamento, com médias de 105,$65 ; 593,50$ e $1105,55 \mathrm{~g} \mathrm{dia}^{-1}$, respectivamente, para o primeiro, segundo e terceiro período de avaliação.

Tabela 2. Médias de consumos de concentrado (CC), de feno (CF), total de matéria seca (CTMS), de água e conversão alimentar da matéria seca (CAMS) de bezerros Holandeses criados em diferentes sistemas de aleitamento artificial até 59 dias de idade

\begin{tabular}{|c|c|c|c|c|c|}
\hline Tratamento $^{1}$ & \multicolumn{2}{|c|}{$\mathrm{CC}\left(\mathrm{gMS} \mathrm{dia}^{-1}\right)$} & \multicolumn{3}{|c|}{ CF $\left(\mathrm{gMS} \mathrm{dia}^{-1}\right)$} \\
\hline Convencional & \multicolumn{2}{|c|}{$539,59^{b}$} & \multicolumn{3}{|c|}{119,05} \\
\hline Fracionado & \multicolumn{2}{|c|}{$663,55^{\mathrm{a}}$} & \multicolumn{3}{|c|}{124,97} \\
\hline $\mathrm{EPM}^{2}$ & \multicolumn{2}{|c|}{59,96} & \multicolumn{3}{|c|}{10,80} \\
\hline \multicolumn{6}{|c|}{ Interações $^{3}$} \\
\hline \multirow{2}{*}{ Sistema } & \multicolumn{3}{|c|}{ Período } & \multirow{2}{*}{$P$} & \multirow{2}{*}{ EPM } \\
\hline & $1^{\circ}(6$ a $25 d)$ & $2^{\circ}(26$ a $45 d)$ & $3^{\circ}(46$ a $59 d)$ & & \\
\hline \multicolumn{6}{|c|}{ CTMS (g MS dia $\left.^{-1}\right)$} \\
\hline Convencional & $173,80^{\mathrm{aC}}$ & $668,45^{\mathrm{aB}}$ & $1155,50^{\mathrm{bA}}$ & \multirow{2}{*}{0,04} & \multirow{2}{*}{59,96} \\
\hline Fracionado & $126,87^{\mathrm{aC}}$ & $810,34^{\mathrm{aB}}$ & $1489,51^{\text {aA }}$ & & \\
\hline \multicolumn{6}{|c|}{ Consumo de água $\left(1\right.$ dia $\left.^{-1}\right)$} \\
\hline Convencional & $1,86^{\mathrm{aB}}$ & $2,39^{\mathrm{aB}}$ & $3,95^{\mathrm{aA}}$ & \multirow{2}{*}{0,01} & \multirow{2}{*}{0,22} \\
\hline Fracionado & $0,81^{\mathrm{aC}}$ & $2,01^{\mathrm{aB}}$ & $5,00^{\mathrm{aA}}$ & & \\
\hline \multicolumn{6}{|c|}{ CAMS (g MS g peso ganho $^{-1}$ ) } \\
\hline Convencional & $0,40^{\mathrm{aA}}$ & $0,81^{\mathrm{aB}}$ & $0,98^{\mathrm{aB}}$ & \multirow{2}{*}{0,01} & \multirow{2}{*}{0,05} \\
\hline Fracionado & $0,20^{\mathrm{aA}}$ & $0,95^{\mathrm{aB}}$ & $1,22^{\mathrm{bC}}$ & & \\
\hline
\end{tabular}

${ }^{\mathrm{I}}$ Médias seguidas de mesma letra na coluna, dentro de cada fator, não se diferem estatisticamente entre si pelo teste de Tukey; ${ }^{2} \mathrm{EPM}=$ Erro padrão das médias; ${ }^{3}$ Médias seguidas por letras minúsculas iguais na coluna ou por letras maiúsculas iguais na linha não se diferem entre si pelo teste de Tukey; As médias de consumo de água foram ajustadas para a covariável peso ao nascimento $(\mathrm{p} \leq 0,05)$.

O consumo de concentrado no primeiro período de avaliação, independente do sistema de aleitamento, foi baixo, com média de $105,65 \mathrm{~g}$ de MS $\operatorname{dia}^{-1}$ (Tabela 2). Silper et al. (2014) observou resultado similar, com consumo médio de $65 \mathrm{~g}$ de $\mathrm{MS}$ dia $^{-1}$ em bezerros criados em diferentes sistemas de aleitamentos. Já animais em aleitamento ad libitum apresentaram consumos médios de concentrado de $90 \mathrm{~g}$ de $\mathrm{MS} \mathrm{dia}^{-1}$ (JASPER \& WEARY, 2002).

$\mathrm{O}$ maior consumo médio de concentrado pelos animais do grupo 
fracionado demonstra que o sistema de aleitamento proposto, mesmo com maiores quantidades de leite fornecidas no início de vida dos animais, favoreceu o consumo desse sólido. Esse resultado pode ter ocorrido pelo fato do aleitamento fracionado ter fornecido um volume de leite superior ao convencional somente nas primeiras semanas de vida dos animais, seguido por reduções graduais, o que acabou gerando estímulo para os animais buscarem o concentrado como opção de alimento para atendimento das suas exigências.

Os consumos de concentrado aumentaram $(\mathrm{p} \leq 0,05)$ de acordo com os períodos, com médias, para ambos os sistemas, de 108,2, 600,49 e 1112,5, respectivamente ao primeiro, segundo e terceiro período de avaliação. Existe relação positiva entre o consumo de concentrado e o desenvolvimento ruminal (BITTAR et al., 2009) e, por isso, esse parâmetro serve como um dos critérios a ser adotado para o desaleitamento de bezerros (ROTH et al., 2009). Tradicionalmente, recomenda-se o desaleitamento de bezerros leiteiros quando o $\mathrm{CC}$ for de aproximadamente $700 \mathrm{~g} \mathrm{dia}^{-1}$, durante três dias consecutivos (QUIGLEY, 1996), o que foi verificado no terceiro período de avaliação, fase próxima ao desaleitamento, para os dois sistemas avaliados nesta pesquisa.

$\mathrm{O}$ consumo de feno não foi influenciado $(\mathrm{p}>0,05)$ pelo sistema de aleitamento (Tabela 2), sendo verificado aumento crescente entre os períodos avaliados, com médias, para ambos os sistemas, de $33,4,127,8$ e 200,7 , respectivamente ao primeiro, segundo e terceiro período de avaliação. Segundo Khan et al. (2011) o fornecimento de feno deve ocorrer no momento de redução da dieta líquida, pois, nessa fase, os animais apresentam menor suprimento de nutrientes via dieta líquida e tendem a procurar fontes alternativas de alimento, ocorrendo estímulo a esse consumo.

O consumo total de matéria seca apresentou interação entre o sistema e os períodos avaliados, refletindo a eficiência do aleitamento fracionado. No terceiro período, fase próxima ao desaleitamento dos animais, esse sistema possibilitou maior $(\mathrm{p} \leq 0,05)$ consumo total de matéria seca quando comparado ao sistema convencional. No primeiro e segundo períodos, os sistemas foram similares $(p>0,05)$, possivelmente pelo baixo consumo de concentrado e de feno no primeiro período e pela quantidade de leite equivalente em ambos os sistemas no segundo período (Tabela 2).

O maior consumo total de matéria seca na fase final nos animais do sistema fracionado demonstra que os mesmos foram estimulados a consumirem maior quantidade de matéria seca após a redução da disponibilidade de dieta líquida, e, possivelmente, esses animais serão desaleitados em condições mais favoráveis para enfrentarem o período de pós- desaleitamento.

Raeth-Knight et al. (2009) relataram melhor crescimento dos bezerros na fase de aleitamento quando o fornecimento de dieta líquida foi superior. Entretanto, autores demonstram que esse sistema pode reduzir o consumo da dieta sólida, gerando impacto negativo no desenvolvimento ruminal (JASPER \& WEARY, 2002), o que não foi encontrado por Azevedo et al. (2013) ao avaliar o desenvolvimento ruminal dos bezerros machos utilizados no presente trabalho.

O maior consumo total de matéria seca observado no terceiro período pelos animais do sistema fracionado evidencia que esse sistema pode ser opção para minimizar a redução de consumo de sólidos apresentada em alguns sistemas de aleitamento intensivos. 
O consumo de água diferiu entre os sistemas de aleitamento dentro dos períodos de avaliação $(p \leq 0,05)$. No sistema convencional, os animais apresentaram consumos similares no primeiro e no segundo períodos, com aumento somente no terceiro período (Tabela 2), possivelmente relacionado ao aumento gradativo do consumo de sólidos. Na oferta fracionada, os consumos foram crescentes entre os períodos, possivelmente como reflexo da redução de consumo de leite $\mathrm{e}$ estímulo ao aumento do consumo de dieta sólida.

Ocorreu interação $(\mathrm{p} \leq 0,05)$ do sistema de aleitamento com os períodos de avaliação para a conversão alimentar da matéria seca (Tabela 2). Houve piora da conversão, nos dois grupos, de acordo com o crescimento e o maior consumo e participação dos alimentos sólidos na dieta total dos animais, resultados justificáveis pela maior digestibilidade e aproveitamento do leite em relação ao concentrado nessa fase de vida, pois, segundo Church (1998), bovinos jovens possuem particularidades fisiológicas e atuação enzimática eficiente que possibilitam o aproveitamento adequado da dieta líquida.

No terceiro período de avaliação, a conversão alimentar dos animais em sistema fracionado foi estatisticamente pior do que a verificada para os animais em aleitamento convencional, justificando-se pela redução da disponibilidade de leite nesse período para os animais do grupo fracionado.

O peso corporal final, o ganho total, o ganho de peso diário, a altura de cernelha e a circunferência torácica foram semelhantes $(p>0,05)$ entre os sistemas de aleitamento (Tabela 3 ).

Tabela 3. Médias de ganho de peso diário (GPD), de ganho total (GT), de peso corporal final (PCF), de altura de cernelha (AC), de circunferência torácica (CT) e incidência de números de dias de diarreia (ID) de bezerros Holandeses criados em diferentes sistemas de aleitamento artificial até 59 dias de idade

\begin{tabular}{lcccccc}
\hline Tratamento & $\begin{array}{c}\mathrm{GPD} \\
\left(\mathrm{g} \mathrm{dia}^{-1}\right)\end{array}$ & $\begin{array}{c}\mathrm{GT} \\
(\mathrm{kg})\end{array}$ & $\begin{array}{c}\mathrm{PCF} \\
(\mathrm{kg})\end{array}$ & $\begin{array}{c}\mathrm{AC} \\
(\mathrm{cm})\end{array}$ & $\begin{array}{c}\mathrm{CT} \\
(\mathrm{cm})\end{array}$ & $\begin{array}{c}\text { ID } \\
(\text { dias })\end{array}$ \\
\hline Convencional & 822,53 & 39,44 & 76,76 & 84,88 & 90,86 & 0,63 \\
Fracionado & 882,65 & 43,72 & 80,31 & 85,14 & 91,22 & 1,31 \\
EPM $^{1}$ & 39,16 & 1,38 & 1,70 & 0,66 & 0,92 & 0,25 \\
\hline
\end{tabular}

${ }^{1} \mathrm{EPM}=$ Erro padrão das médias; As médias de PCF, AC e CT foram ajustadas para a covariável peso ao nascimento $(\mathrm{p} \leq 0,05)$.

O ganho de peso diário médio dos animais, de ambos os grupos, aumentou a cada período de avaliação, sendo observados ganhos de 564,06; 816,22 e $1177,48 \mathrm{~g} \mathrm{dia}{ }^{-1}$, respectivamente ao primeiro, segundo e terceiro período de avaliação.

A similaridade de ganhos de peso entre os grupos para o primeiro e segundo período se deve à semelhança do consumo total de matéria seca. Já no terceiro período, apesar dos animais do grupo fracionado apresentarem maior consumo total de matéria seca, os mesmos apresentaram pior conversão alimentar nessa fase, justificando a similaridade no ganho pelos mesmos no período final.

É importante ressaltar que, no terceiro período de avaliação, os animais aleitados de forma fracionada estavam recebendo a metade de dieta líquida 
quando comparados aos animais aleitados de forma convencional e, mesmo assim, os mesmos, não reduziram o ganho de peso nessa fase.

$\mathrm{O}$ fornecimento fracionado de sucedâneo proporcionou maior PCF dos animais no trabalho de Khan et al. (2007). Entretanto, no trabalho de Silper et al. (2014), os ganhos corporais observados nos períodos próximos ao desaleitamento foram similares entre os grupos de animais aleitados com maiores volumes, volumes convencionais ou volumes fracionados de sucedâneo.

Em conformidade com Van Amburgh e Drackley (2005), 20\% da variação na primeira produção de leite de novilhas leiteiras podem relacionar-se à taxa de crescimento até o desaleitamento. Para controlar isso, os autores sugerem taxas de crescimentos ideais em que os animais dobrem o peso corporal inicial até $\mathrm{o}$ desaleitamento, o que foi constatado nos dois sistemas de aleitamento avaliados no presente trabalho (Tabela 3).

A altura de cernelha e a circunferência torácica não foram influenciadas $(\mathrm{p}>0,05)$ pelos sistemas de aleitamento, o que pode relacionar-se ao observado para os ganhos médios diários e ao peso corporal final. Segundo Gonsalves Neto et al. (2008), a altura de cernelha e o perímetro torácico são mensurações utilizadas para estimar o tamanho do esqueleto, sendo medidas fundamentais para a avaliação do crescimento e do desenvolvimento dos animais.

A incidência de dias com diarreia não foi influenciada $(\mathrm{p}>0,05)$ pelo sistema $\mathrm{e}$ pelos períodos de avaliação e não foi demonstrada interação $(p>0,05)$ entre os sistemas e os períodos de avaliação para esse parâmetro. Apesar do aumento da quantidade de leite fornecido acima da convencional provocar receio nos produtores, por acreditarem em aumento de diarreia, esse incremento não causa diarreia nos animais segundo diversos estudos (JASPER \& WEARY, 2002; KHAN et al., 2007), de maneira semelhante ao observado na presente pesquisa, pois houve similaridade entre as incidências observadas durante 0 primeiro período em ambos os sistemas (Tabela 3).

Os resultados da análise econômica (Tabela 4) dos dois sistemas de aleitamento demonstraram que o custo do feno representou $3,10 \%$ dos custos médios dos dois sistemas, seguido pelo concentrado (13\%) e o leite (84\%). Durante o aleitamento, o custo do feno, pelo baixo consumo e por ser relativamente barato, quando comparado ao leite, foi pouco representativo no custo das dietas.

Tabela 4. Médias de consumo e custo total de leite (CTL), de concentrado (CTC) e de feno (CTF), de custo de oportunidade (CO; R\$), de ganho de peso total (GPT) e de custo por ganho de peso total (CGPT; R $\$ \mathrm{~kg}^{-1} \mathrm{GPT}$ ) de bezerros Holandeses criados em diferentes sistemas de aleitamento artificial até 59 dias de idade

\begin{tabular}{|c|c|c|c|c|c|c|c|}
\hline Sistema & Variável & Consumo & $(\mathrm{R} \$)$ & Custo (R\$) & $\mathrm{CO}(\mathrm{R} \$)$ & $\begin{array}{l}\text { GPT } \\
(\mathrm{kg}) \\
\end{array}$ & $\begin{array}{c}\text { CGPT } \\
\left(\mathrm{R} \$ \mathrm{~kg}^{1} \mathrm{GPT}\right)\end{array}$ \\
\hline \multirow{3}{*}{ Convencional } & CTL (1) & 216,00 & 0,73 & 157,68 & \multirow{3}{*}{186,24} & \multirow{3}{*}{39,44} & \multirow{3}{*}{4,72} \\
\hline & CTC $(\mathrm{kg}){ }^{*}$ & 28,64 & 0,80 & 22,91 & & & \\
\hline & $\mathrm{CTF}(\mathrm{kg}){ }^{*}$ & 6,28 & 0,90 & 5,65 & & & \\
\hline \multirow{3}{*}{ Fracionado } & CTL (1) ${ }^{*}$ & 228,00 & 0,73 & 166,44 & \multirow{3}{*}{199,62} & \multirow{3}{*}{43,72} & \multirow{3}{*}{4,56} \\
\hline & CTC $(\mathrm{kg})^{*}$ & 33,61 & 0,80 & 26,89 & & & \\
\hline & CTF (kg) ${ }^{*}$ & 6,99 & 0,90 & 6,29 & & & \\
\hline
\end{tabular}

*Matéria natural. 
O custo operacional foi superior para o sistema fracionado, com diferença de $\mathrm{R} \$ 13,38$ por animal. Esse resultado pode ser explicado pelo maior consumo de leite no primeiro período e pelo maior consumo total de matéria seca do concentrado pelos animais no sistema fracionado (Tabela 2). Observa-se que o custo com concentrado foi $14,8 \%$ superior no sistema fracionado quando comparado ao convencional, seguido pelo feno e pelo leite, o qual representou $5,26 \%$ de aumento no custo do sistema fracionado.

Mesmo com o maior custo operacional no sistema fracionado, o custo por ganho de peso total dos animais nesse grupo foi $3,51 \%$ inferior ao convencional, possivelmente pelo maior valor numérico do ganho total dos animais aleitados de forma fracionada.

Observa-se que o sistema de aleitamento fracionado possibilitou maior consumo total de matéria seca pelos animais no período anterior ao desaleitamento. Mesmo apresentando ganhos de peso, desenvolvimento, peso corporal final e incidência de dias com diarreia ao desaleitamento similares, os animais mantidos em sistema de aleitamento fracionado apresentaram menor custo por $\mathrm{kg}$ de peso ganho.

\section{REFERÊNCIAS}

AZEVEDO, R.A.; ARAÚJO, L.; DUARTE, D.V.; CRUZ, M.S.; COSTA, S.F.; OLIVEIRA, N.J.F.; DUARTE, E.R.; GERASEEV, L.C. Development of the digestive tract of dairy calves reared in a fractionated nursing system. Pesquisa Veterinária Brasileira, v.33, n.7, p.931-936, 2013.
BITTAR, C.M.M.; FERREIRA, L.S.; SANTOS, F.A.P.; ZOPOLLATO, M. Performance and ruminal development of dairy calves fed starter concentrate with different physical forms. Revista Brasileira de Zootecnia, v.38, n.8, p.1561-1567, 2009.

BROWN, E.G.; VANDEHAAR, M.J.; DANIELS, K.M.; LIESMAN, J.S. CHAPIN, L.T.; KEISLER, D.H. NIELSEN, M.S. Effect of increasing energy and protein intake on body growth and carcass composition of heifer calves. Journal of Dairy Science, v.88, n.2, p.585-594, 2005.

\section{CENTRO DE ESTUDOS}

AVANÇADOS EM ECONOMIA APLICADA - CEPEA, 2011. Preços ao produtor. Disponível em: $<$ http://www.cepea.esalq.usp.br/leite/?p age $=155>$. Acesso em: 21 out. 2012.

CHURCH, D.C. The ruminant: animal digestive physiology and nutrition. Englewood Cliffs, NJ: Pentice-Hall, 1998. 564p.

GODDEN, S.M.; FETROW, J.P.; FEIRTAG, J.M.; GREEN, L.R.; WELLS, S.J. Economic analysis of feeding pasteurized nonsaleable milk versus conventional milk replacer to dairy calves. Journal of the American Veterinary Medical Association, v.226, n.9, p.1547-1554, 2005.

GONSALVES NETO, J.; SILVA, F.F.; BONOMO, P.;NASCIMENTO, P.V.N.; FERNANDES, S.A.A.; PEDREIRA, M.S.; VELLOSO, C.M.; TEXEIRA, F.A. Performance of Holstein calves fed ground or pelleted concentrate. Revista Brasileira de Saúde e Produção Animal [online], v.9, n.4, p.726-733, 2008. 
HILL, T.M.; ALDRICH, J.M., SCHLOTTERBECK, R.L.; BATEMAN II, H.G. Effects of feeding rate and concentrations of protein and fat of milk replacers fed to neonatal calves. The Professional Animal Scientist, v.22, n.5, p.374-381, 2006.

JASPER, J.; WEARY, D.M. Effects of ad libitum milk intake on dairy calves. Journal of Dairy Science, v.85, n.11, p.3054-3058, 2002.

JENSEN, M.B.; HOLM, L. The effect of milk flow rate and milk allowance on feeding behaviour in dairy calves fed by computer controlled milk feeders.

Applied Animal Behaviour Science, v.82, n.2, p.87-100, 2003.

KHAN, M.A.; LEE, H.J.; LEE, W.S.; KIM, H.S.; KIM, S.B.; KI, K.S.; HA, J.K.; LEE, H.G.; CHOI, Y.J. Pre- and postweaning performance of Holstein female calves fed milk through stepdown and conventional methods.

Journal of Dairy Science, v.90, n.2, p.876-885, 2007.

KHAN, M.A.; WEARY, D.M.; Von KEYSERLINGK, M.A.G. Hay intake improves performance and rumen development of calves fed higher quantities of milk. Journal of Dairy Science, v.94, p.3547-3553, 2011.

KMICIKEWYCZ, A.D; SILVA, D.N.L. da; LINN, J.G.; LITHERLAND, N.B. Effects of milk replacer program fed 2 or 4 times daily on nutrient intake and calf growth. Journal of Dairy Science, v.96, n.2, p.1125-1134, 2013.

LE HUEROU-LURON, I.; GUILLOTEAU, P.; WICKERPLANQUART, C.; CHAYVIALLE, JA.; BURTON, J.; MOUATS, A.; TOULLEC, R.; PUIGSERVER, A. Gastric and pancreatic enzyme activities and their relationship with some gut regulatory peptides during postnatal development and weaning in calves. Journal of Nutrition, v.122, n.7, p.1434-1435, 1992.

LIMA, R.N.; LIMA, P.O.; AROEIRA, L.J.M.; MIRANDA, M.V.F.G.; LOPES, K.T.L.; DIÓGENES, G.V.; PEREIRA, M.I.B.; SOUZA, I.T.N.; ROSSATO, C.H. Performance of calves fed cheese whey associated with colostrum.

Pesquisa Agropecuária Brasileira, v.47, n.8, p.1174-1180, 2012.

\section{LUCCI, C. Bovinos Leiteiros Jovens.}

São Paulo: Nobel, 1989.

ORSKOV, E.R. Starch digestion and utilization in ruminants. Journal of Animal Science, v.63, n.5, p.16241633, 1986.

PASSILLÉ, A.M. de; MARNET, P.G. LAPIERRE, H.; RUSHEN, J. Effects of nursing on milk ejection and milk yield during nursing and milking in dairy cows. Journal of Dairy Science, v.91, n.4, p.1416-1422, 2008.

QUIGLEY, J.D. Effects of lasalocid in milk replacer and calf starter on growth, intake, and fecal oocyst shedding in calves challenged with Eimeria.

Journal of Dairy Science, v.79, n.1, p.154, 1996. Supl.

RAETH-KNIGHT, M.; CHESTERJONES, H.; HAYES, S.; LINN, J.; LARSON, R.; ZIEGLER, D.; ZIEGLER, B.; BROADWATER, N. Impact of conventional or intensive milk replacer programs on Holstein heifer performance through six months of age and during first lactation.

Journal of Dairy Science, v.92, n.2, p.799-809, 2009. 
ROTH, B.A.; KEIL, N.M.; GYGAX, L.; HILLMANN, E. Influence of weaning method on health status and rumen development in dairy calves.

Journal of Dairy Science, v.92, n.2, p.645-656, 2009.

SWEENEY, B.C.; RUSHEN, J.; WEARY, D.M.; PASSILLÉ, A.M. de. Duration of weaning, starter intake and weight gain of dairy calves fed large amounts of milk. Journal of Dairy Science, v.93, n.1, p.148-152, 2010.

STATISTICAL ANALYSIS SYSTEM. SAS user's guide. Version 9.0. Cary, SAS Institute, 2002.

SILPER, B.F.; LANA, A.M.Q.; CARVALHO, A.U.; FERREIRA, C.S.; FRANZONI, A.P.S.; LIMA, J.A.M.; SATURNINO, H.M.; REIS, R.B.; COELHO, S.G. Effects of milk replacer feeding strategies on performance, ruminal development, and metabolism of dairy calves. Journal of Dairy Science, v.97, n.2, p.1016-1025, 2014.

SILVA, D.J.; QUEIROZ, A.C. Análise de alimentos: métodos químicos e biológicos. 3.ed. Viçosa: Universidade Federal de Viçosa, 2002. 235p.

UYS, J.L.; LOURENS, D.C.; THOMPSON, P.N. The effect of unrestricted milk feeding on the growth and health of Jersey calves. Journal of the South African Veterinary Association, v.82, n.1, p.47-52, 2011.
Van AMBURGH, M.; DRACKLEY, J. Current perspectives on the energy and protein requirements of the pre-weaned calf. In: GARNSWORTHY, P.C. (Ed.). Calf and heifer rearing: principles of rearing the modern dairy heifer from calf to calving. Nottingham:

Nottingham University Press, 2005. p.67-82.

VIEIRA, A. de P.; GUESDON, V.; DE PASSILLÉ, A.M.; VON

KEYSERLINGK, M.A.G.; WEARY, D.M. Behaviour indicators of hunger in dairy calves. Applied Animal

BehaviourScience, v.109, n.2, p.180189, 2008.

Von KEYSERLINGK, M.A.G.; RUSHEN, J.; DE PASSILLÉ, A.M.B.; WEARY, D.M. Invited review: The welfare of dairy cattle-key concepts and the role of science. Journal of Dairy Science, v.92, n.9, p.4101- 4111, 2009.

Data de recebimento: $15 / 07 / 2013$

Data de aprovação: 28/03/2014 